\section{STATMAT}

(Jurnal Statistika dan Matematika)

\title{
ANALISIS KONSENTRASI PM2.5 SELAMA PENYELENGGARAAN ASIAN GAMES KE-18 DI JAKARTA
}

\author{
Rista Hernandi Virgianto ${ }^{1)}$ dan Dzikrullah Akbar ${ }^{2)}$ \\ 1) 2) Program Studi Klimatologi, Sekolah Tinggi Meteorologi Klimatologi dan Geofisika \\ Jl. Perhubungan I No. 5, Pondok Betung, Bintaro, Tangerang 15211 \\ rista.virgianto@stmkg.ac.id
}

\begin{abstract}
Good air quality is very important for public health. The air quality during the $18^{\text {th }}$ Asian Games event in Jakarta became an international issue that greatly influenced the reputation of Jakarta. This study aims to determine the air quality in Jakarta during the $18^{\text {th }}$ Asian Games event based on the PM 2.5 concentration. The observation data were taken from two points, at Central Jakarta and South Jakarta. The Mann-Whitney U test as a non-parametric test was used to determine the significant changes in $P M_{2.5}$ concentration before, during and after the $18^{\text {th }}$ Asian Games event. Results showed that the mean concentration of PM2.5 before the 18th Asian Games in South Jakarta is 67.9 $\mu \mathrm{g} / \mathrm{m}^{3}$ which exceeded allowed threshold. All test results showed that there are significant changes in PM 2.5 concentration for all period at both observation points. The notable decline in concentration between the period before and after the 18th Asian Games occurred on Tuesday at both observation points. While the lowest decrease in concentration occurred on Sunday in Central Jakarta and Friday in South Jakarta.
\end{abstract}

Keywords: Air Quality, PM2.5, Mann-Whitney U Test, non-parametric.

\begin{abstract}
ABSTRAK
Kualitas udara yang baik sangat penting bagi kesehatan masyarakat. Kualitas udara selama ajang Asian Games ke-18 di Jakarta menjadi masalah internasional yang sangat mempengaruhi reputasi Jakarta. Penelitian ini bertujuan untuk menentukan kualitas udara di Jakarta selama acara Asian Games ke-18 berdasarkan konsentrasi PM2.5. Data pengamatan diambil dari dua titik, di Jakarta Pusat dan Jakarta Selatan. Uji U MannWhitney sebagai tes non-parametrik digunakan untuk menentukan perubahan signifikan dalam konsentrasi $\mathrm{PM}_{2.5}$ sebelum, selama dan setelah acara Asian Games ke-18. Hasil penelitian menunjukkan bahwa konsentrasi rata-rata $\mathrm{PM}_{2.5}$ sebelum Asian Games ke-18 di Jakarta Selatan adalah $67,9 \mu \mathrm{g} / \mathrm{m}^{3}$ yang melebihi ambang batas. Semua hasil tes menunjukkan bahwa ada perubahan yang signifikan dalam konsentrasi $\mathrm{PM}_{2.5}$ untuk semua periode di kedua titik pengamatan. Penurunan konsentrasi yang mencolok antara periode sebelum dan sesudah Asian Games ke-18 terjadi pada hari Selasa di kedua titik pengamatan. Sedangkan penurunan konsentrasi terendah terjadi pada hari Minggu di Jakarta Pusat dan Jumat di Jakarta Selatan.
\end{abstract}

Kata kunci: Kualitas Udara, PM2.5, Uji U Mann-Whitney, non-parametrik. 


\section{STATMAT}

(Jurnal Statistika dan Matematika)

\section{PENDAHULUAN}

Kualitas udara yang buruk menjadi tanda tercemarnya udara melalui proses tercampurnya unsur-unsur berbahaya ke udara. Sumber pencemaran di kota-kota besar seperti Jakarta masih didominasi oleh kendaraan bermotor (Kusminingrum dan Gunawan, 2008). Salah satu komponen polutan di udara yang berdampak besar terhadap kesehatan adalah Particulate Matter (PM). PM merupakan klasifikasi fisik umum partikel yang ditemukan di udara, seperti debu, kotoran, jelaga dan asap. PM bukan merujuk pada entitas kimia tertentu tetapi merupakan campuran partikel dari sumber yang berbeda dengan berbagai ukuran, komposisi, dan sifat (Vallero, 2014). Sementara itu, menurut Dockery, dkk. (1993) kematian akibat kardiovaskular dan kanker paru-paru masingmasing positif terkait dengan konsentrasi ambien $\mathrm{PM}_{2.5}$ dan berkurangnya PM2.5 dapat menurunkan risiko kematian akibat polusi udara selama 1970 sampai 1990.

Banyak tulisan mengenai yang kurang tepat dalam mendefiniskan $\mathrm{PM}_{2.5}$ dengan PM yang berukuran diameter lebih kecil dari 2,5 $\mu$ m. Sedangkan definisi standar dari $\mathrm{PM}_{2.5}$ sendiri adalah konsentrasi massa dari PM untuk partikel yang melewati inlet atau pipa saringan selektif yang memiliki efisiensi 50\% pada diameter aerodinamik sebesar 2,5 $\mu \mathrm{m}$ (ISO, 1995; Tiwary dan Jeremy, 2010). Sementara itu, $\mathrm{PM}_{2.5}$ juga merupakan merupakan salah satu dari 12 parameter pencemar udara yang ambang batasnya diatur dalam Peraturan Pemerintah Republik Indonesia No. 41 Tahun 1999 dengan rata-rata harian sebesar $65 \mu \mathrm{g} / \mathrm{m}^{3}$ (Republik Indonesia, 1999). Ukuran yang sangat kecil membuat $\mathrm{PM}_{2.5}$ dapat langsung masuk ke dalam alveoli paru-paru dengan permukaannya yang dapat menyerap sejumlah besar bahan beracun dan berbahaya dan memasuki sistem sirkulasi 


\section{STATMAT}

(Jurnal Statistika dan Matematika)

darah sehingga menuju organ-organ lain, akhirnya dapat menyebabkan kerusakan struktur dan fungsi pada sistem pernapasan dan lainnya (Dong-Qun dan Wen-Li, 2004).

Kualitas udara di Kota Jakarta sangat penting bagi penduduk yang tinggal maupun bagi yang sehari-hari bekerja. Kepadatan lalu lintas yang sangat tinggi dan kurangnya ruang terbuka hijau di Jakarta membuat kualitas udara di kota yang merupakan Ibukota Indonesia ini menjadi perhatian masyarakat Indonesia dan dunia Internasional. Kualitas udara yang buruk di Jakarta menjelang ajang olahraga terbesar di Asia yaitu Asian Games ke-18 tahun 2018 juga banyak dibahas oleh media Internasional (Aljazeera, 2018; Reuters, 2018). Sebelum ajang Asian Games ke-18 dibuka, Pemerintah Daerah DKI Jakarta mengeluarkan aturan ganjil-genap yang dimulai pukul 07.00-10.00 WIB dan 16.00-20.00 WIB selama Asian Games berlangsung dari tanggal 18 Agustus hingga 2 September 2018 untuk memperbaiki kualitas udara yang banyak disebabkan oleh tingginya kepadatan lalu lintas (Kompas, 2018).

Berdasarkan uraian masalah di atas, penelitian ini dilakukan untuk mengetahui keadaan kualitas udara di Jakarta sebelum, sesaat dan setelah ajang Asian Games k-18 berlangsung dengan menganalisis konsentrasi $\mathrm{PM}_{2.5}$ yang datanya diperoleh dari alat pemantauan kualitas udara.

\section{DATA DAN METODOLOGI PENELITIAN}

\subsection{Data}

Penelitian ini mencakup wilayah Jakarta Pusat dan Jakarta Selatan dengan menggunakan data konsentrasi $\mathrm{PM}_{2.5}$ per jam dalam satuan $\mu \mathrm{g} / \mathrm{m}^{3}$ yang diperoleh dari dua 


\section{STATMAT}

(Jurnal Statistika dan Matematika)

titik pengamatan $\mathrm{PM}_{2.5}$ milik Kedutaan Besar Amerika Serikat yang dapat diunduh dari situs web AirNow (https://airnow.gov). Posisi alat pengamatan $\mathrm{PM}_{2.5}$ secara geografis dapat dilihat pada gambar 2.1. Periode data yang digunakan adalah tanggal 23 Juli 2018 pukul 00.00 WIB sampai September 2018 pukul 23.00 WIB.

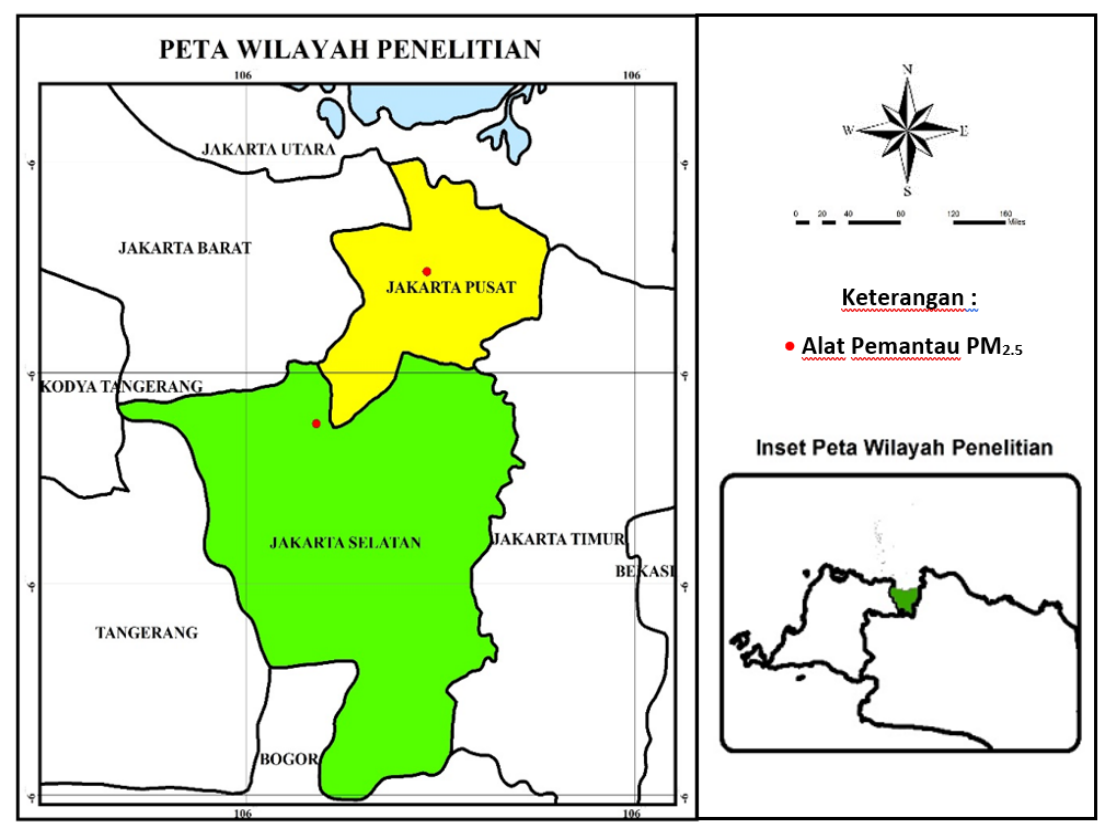

Gambar 2.1. Peta Wilayah Penelitian.

\subsection{Metode}

Pengendalian mutu dilakukan terhadap data konsentrasi $\mathrm{PM}_{2.5}$ dengan mengabaikan data yang memiliki nilai negatif karena tidak memunginkan konsentrasi suatu zat bernilai di bawah nol. Selanjutnya data disusun dalam format tiap jam. Kemudian data akan dianalisis untuk setiap periode sebelum (23 Juli sampai 12 Agustus 2018), saat (13 
STATMAT

(Jurnal Statistika dan Matematika)

Agustus sampai 2 September 2018) dan setelah (3 September sampai 23 September 2018)

Asian Games ke-18 dengan lama untuk masing masing periode 3 minggu.

Analisis data konsentrasi $\mathrm{PM}_{2.5}$ menggunakan statistika deskriptif untuk mendapatkan generalisasi berdasarkan sampel konsentrasi $\mathrm{PM}_{2.5}$. Statistik deskriptif yang digunakan mencakup nilai rata-rata, median, standar deviasi, serta nilai maksimum dan minimum.

1. Nilai rata-rata

Penghitungan rata-rata dilakukan dengan menjumlahkan seluruh nilai data suatu kelompok sampel, kemudian dibagi dengan jumlah sampel tersebut. Perhitungan rata-rata konsentrasi $\mathrm{PM}_{2.5}$ per jam menjadi konsentrasi $\mathrm{PM}_{2.5}$ per periode waktu dirumuskan sebagai berikut (Sugiyono, 2006) :

$$
\bar{x}=\frac{1}{n} \sum_{i=1}^{n} x_{i}
$$

Keterangan :

$\bar{x}=$ Rata-rata dari suatu sampel

$x_{i}=$ Nilai dari data ke- $\mathrm{i}$

$n=$ Jumlah data dari sampel 
(Jurnal Statistika dan Matematika)

2. Nilai median

Median adalah ukuran pemusatan dimana data tersebut terbagi menjadi dua sama banyak. Untuk data yang belum dikelompokkan, data tersebut diurutkan terlebih dahulu dari data yang terkecil hingga data yang terbesar. Perhitungan median konsentrasi $\mathrm{PM}_{2.5}$ dirumuskan sebagai berikut (Nugroho, 2007) :

$$
\begin{array}{ll}
\text { Me }=\frac{X_{\left(\frac{n}{2}\right)}+X_{\left(\frac{n}{2}+1\right)}}{2} \quad, \text { jika } n \text { genap } \\
\text { Me }=X_{\left(\frac{n+1}{2}\right)} \quad \text {,jika } n \text { ganjil }
\end{array}
$$

\section{Keterangan :}

$\mathrm{Me}=$ Median

$X \quad=$ Nilai data

$n \quad=$ Jumlah data dari sampel

3. Standar deviasi

Standar deviasi merupakan pilihan dari ukuran penyebaran dengan menggunakan satuan yang sama dengan ukuran datanya. Standar deviasi konsentrasi $\mathrm{PM}_{2.5}$ dirumuskan sebagai berikut (Nugroho, 2007) :

$$
S=\frac{\sqrt{\sum_{i=1}^{n} x_{i}{ }^{2}-\frac{\left(\sum_{i=1}^{n} x_{i}\right)^{2}}{n}}}{n-1}
$$

Keterangan :

$\mathrm{S}=$ Standar deviasi 


\section{STATMAT}

(Jurnal Statistika dan Matematika)

$x_{i}=$ Nilai dari data ke- $\mathrm{i}$

$n \quad=$ Jumlah data dari sampel

\section{Nilai maksimum dan minimum}

Uji U Mann-Whitney adalah uji alternatif non-parametrik untuk uji-t sampel independen. Metode tersebut merupakan uji non-parametrik yang digunakan untuk membandingkan dua apakah dua sampel berasal dari populasi yang sama, dan digunakan untuk menguji apakah distribusi kedua sampel tersebut sama atau tidak. Biasanya, uji U Mann-Whitney digunakan ketika asumsi uji-t atau asumsi distribusi normal tidak terpenuhi. Sehingga, penelitian ini menggunakan uji U Mann-Whitney untuk menguji perbedaan rata-rata konsentrasi $\mathrm{PM}_{2.5}$ antara dua periode yang berbeda.

Terkadang memahami uji U Mann-Whitney sulit diinterpretasikan karena hasilnya disajikan dalam perbedaan peringkat kelompok daripada perbedaan rata-rata kelompok. Uji U Mann-Whitney adalah tes non-parametrik, sehingga tidak perlu mengasumsikan distribusi (Wilks, 2011). Namun, ada beberapa hal yang diasumsikan, yaitu sampel yang diambil dari populasi adalah acak dan sampel saling independen. Uji U Mann Whitney digunakan sebagai uji signikansi untuk membandingkan dua kelompok data yang tidak saling berkaitan. Sehingga, penelitian ini menggunakan uji U Mann-Whitney untuk menguji apakah terjadi perubahan nilai konsentrasi $\mathrm{PM}_{2.5}$ antar periode sebelum, sesaat dan setelah ajang Asian Games ke-18 di Jakarta. Hipotesis nol $\left(\mathrm{H}_{0}\right)$ yang digunakan dalam uji ini adalah bahwa dua sampel data diambil dari distribusi yang sama. Sebaliknya, Hipotesis alternatif $\left(\mathrm{H}_{1}\right)$ yang digunakan adalah bahwa data dua sampel data diambil dari distribusi yang berbeda (Gibbons dan Chakraborti, 2003). 
Langkah-langkah dalam uji U Mann-Whitney adalah sebagai berikut.

a) Menghitung U untuk dua periode data dengan rumus (Zar, 1996),

$$
U_{1}=R_{1}-\frac{n_{1}\left(n_{1}+1\right)}{2}
$$

dan

$$
U_{2}=R_{2}-\frac{n_{2}\left(n_{2}+1\right)}{2},
$$

dengan

$U_{1}=$ nilai $\mathrm{U}$ untuk periode 1

$U_{2}=$ nilai $\mathrm{U}$ untuk periode 2

$n_{1}=$ jumlah sampel periode 1

$n_{2}=$ jumlah sampel periode 2

$R_{1}=$ jumlah rangking sampel untuk periode 1

$R_{2}=$ jumlah rangking sampel untuk periode 2

b) Menentukan U terkecil dari dua periode data

c) Menentukan nilai kritis dari U dengan $\alpha=0,05$

d) Membandingkan $U$ terkecil dengan nilai kritis dari $U$

e) Memutuskan apakah $\mathrm{H}_{0}$ diterima atau ditolak

\section{HASIL DAN PEMBAHASAN}

\subsection{Perbandingan Distribusi Konsentrasi PM $\mathbf{P M}_{2.5}$ sebelum, saat dan setelah Asian}

\section{Games ke-18}

Berdasarkan data pengamatan $\mathrm{PM}_{2.5}$ di Jakarta Pusat, rata-rata konsentrasi untuk periode sebelum $\left(57,7 \mu \mathrm{g} / \mathrm{m}^{3}\right)$, saat $\left(44,4 \mu \mathrm{g} / \mathrm{m}^{3}\right)$, dan setelah Asian Games ke-18 $(38,5$ $\mu \mathrm{g} / \mathrm{m}^{3}$ ) masih di bawah ambang batas yang ditentukan yaitu $65 \mu \mathrm{g} / \mathrm{m}^{3}$. Standar deviasi 
STATMAT

(Jurnal Statistika dan Matematika)

untuk periode sebelum $\left(25,5 \mu \mathrm{g} / \mathrm{m}^{3}\right)$ lebih besar daripada saat $\left(19,4 \mu \mathrm{g} / \mathrm{m}^{3}\right)$, dan setelah $\left(19,0 \mu \mathrm{g} / \mathrm{m}^{3}\right)$ Asian Games ke-18 di Jakarta Pusat. Sedangkan di Jakarta Selatan, rata-rata konsentrasi untuk periode sebelum Asian Games ke-18 $\left(67,9 \mu \mathrm{g} / \mathrm{m}^{3}\right)$ melebihi ambang batas yang ditentukan. Namun, saat $\left(55,9 \mu \mathrm{g} / \mathrm{m}^{3}\right)$ dan setelah Asian Games ke-18 $(40,1$ $\left.\mu \mathrm{g} / \mathrm{m}^{3}\right)$ masih di bawah ambang batas. Standar deviasi untuk periode sebelum $(26,3$ $\left.\mu \mathrm{g} / \mathrm{m}^{3}\right)$ lebih besar daripada saat $\left(21,6 \mu \mathrm{g} / \mathrm{m}^{3}\right)$, dan setelah $\left(20,2 \mu \mathrm{g} / \mathrm{m}^{3}\right)$ Asian Games ke18 di Jakarta Selatan.
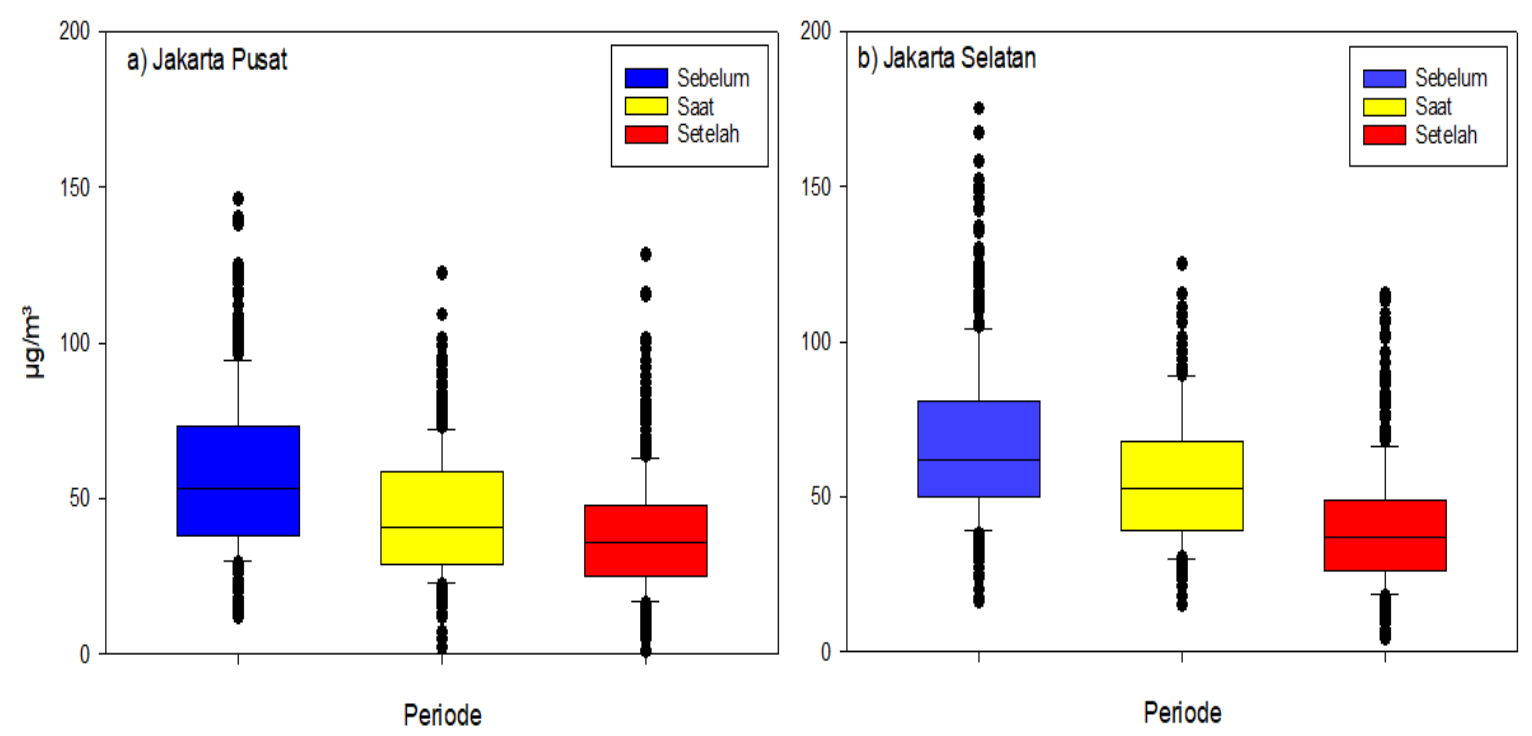

Gambar 3.1. Boxplot Perbandingan Distribusi Konsentrasi $\mathbf{P M}_{2.5}$ sebelum, saat dan setelah Asian Games ke-18 di a) Jakarta Pusat dan b) Jakarta Selatan.

Konsentrasi $\mathrm{PM}_{2.5}$ secara umum mengalami penurunan mulai dari periode sebelum, saat, dan setelah Asian Games ke-18 di kedua lokasi pengamatan dengan perbandingan distribusi seperti ditunjukkan gambar 3.1. Konsentrasi $\mathrm{PM}_{2.5}$ sebelum Asian Games ke18 lebih tinggi di Jakarta Selatan dengan nilai median $62 \mu \mathrm{g} / \mathrm{m}^{3}$ dibandingkan dengan di Jakarta Pusat dengan nilai median $53 \mu \mathrm{g} / \mathrm{m}^{3}$. Pada periode ini di Jakarta Selatan memiliki 


\section{STATMAT}

(Jurnal Statistika dan Matematika)

banyak nilai konsentrasi per jam diatas $100 \mu \mathrm{g} / \mathrm{m}^{3}$. Begitu juga saat Asian Games ke-18, Konsentrasi $\mathrm{PM}_{2.5}$ di Jakarta Selatan dengan nilai median $52,5 \mu \mathrm{g} / \mathrm{m}^{3}$ sedikit lebih tinggi dibandingkan dengan di Jakarta Pusat dengan nilai median $41 \mu \mathrm{g} / \mathrm{m}^{3}$. Namun, pada periode setelah Asian Games ke-18, distribusi konsentrasi PM$_{2.5}$ di Jakarta Selatan dengan median $37 \mu \mathrm{g} / \mathrm{m}^{3}$ hampir sama dengan di Jakarta Pusat dengan median $36 \mu \mathrm{g} / \mathrm{m}^{3}$. Berdasarkan gambar 3.1, kita juga mengetahui bahwa konsentrasi di setiap periode pada kedua titik pengamatan tidak memenuhi kriteria distribusi normal, untuk itu uji U MannWhitney sebagai uji non-parametrik sangat tepat dilakukan untuk mengetahui ada tidaknya perubahan konsterasi $\mathrm{PM}_{2.5}$ antar periode di setiap titik pengamatan.

Berdasarkan gambar 3.2, konsentrasi harian tertinggi $\mathrm{PM}_{2.5}$ untuk periode sebelum Asian Games ke-18 di kedua titik pengamatan terjadi pada hari Rabu dan terendah pada hari Jumat. Pada periode setelah Asian Games ke-18, konsentrasi harian tertinggi $\mathrm{PM}_{2.5}$ di kedua titik pengamatan terjadi pada hari Minggu, sedangkan terendah pada hari Sabtu di Jakarta Pusat dan hari Selasa di Jakarta Selatan. Namun, konsentrasi $\mathrm{PM}_{2.5}$ tidak jauh berbeda setiap harinya pada periode saat Asian Games ke-18. Penurunan konsentrasi terbesar antara periode sebelum dan setelah Asian Games ke-18 tejadi pada hari Selasa di kedua titik pengamatan yaitu sebesar 44\% di Jakarta Pusat dan 59\% di Jakarta Selatan. Sedangkan penurunan konsentrasi terendah terjadi pada hari Minggu di Jakarta Pusat sebesar $12 \%$ dan hari Jumat di Jakarta Selatan sebesar $8 \%$.
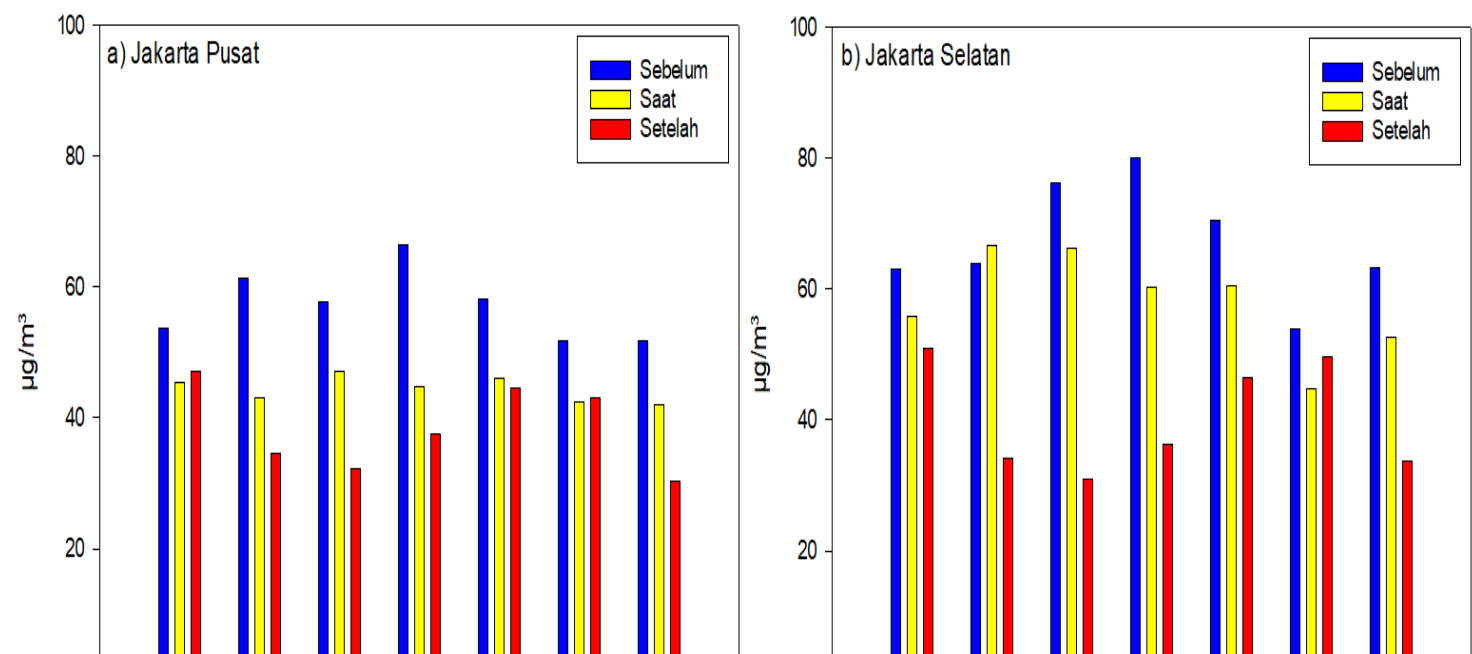
Gambar 3.2. Grafik Perbandingan Konsentrasi harian $\mathrm{PM}_{2.5}$ sebelum, saat dan setelah Asian Games ke-18 di a) Jakarta Pusat dan b) Jakarta Selatan.

Hasil uji signifikansi perubahan konsentrasi antar periode menunjukkan bahwa terdapat perbedaan konsentrasi $\mathrm{PM}_{2.5}$ untuk periode sebelum, saat dan sesudah Asian Games ke-18 di kedua lokasi pengamatan. Semua hasil uji siginifikansi tersebut menunjukkan nilai parameter Mann-Whitney (U) yang lebih kecil dari nilai kritis serta $p$ value yang lebih kecil dari 0,001 pada tingkat signifikansi 5\% $(\alpha=0,05)$.

Tabel 3.1. Hasil Uji U Mann-Whitney 
STATMAT

(Jurnal Statistika dan Matematika)

\begin{tabular}{|c|c|c|c|c|c|}
\hline Lokasi & $\begin{array}{c}\text { Periode terhadap } \\
\text { Asian Games ke-18 }\end{array}$ & $\mathrm{U}$ & Nilai & $p$ - & Simpulan \\
Jakarta & Sebelum dan Saat & $77.539,5$ & $247.876,5$ & $<0,001$ & $\mathrm{H}_{0}$ ditolak; $\mathrm{H}_{1}$ \\
diterima
\end{tabular}

\section{SIMPULAN DAN SARAN}

\subsection{SIMPULAN}

Simpulan penelitian ini yaitu:

1) Rata-rata konsentrasi $\mathrm{PM}_{2.5}$ di Jakarta Selatan lebih tinggi daripada di Jakarta Pusat baik untuk setiap periode maupun rata-rata harian. 


\section{STATMAT}

(Jurnal Statistika dan Matematika)

2) Rata-rata konsentrasi $\mathrm{PM}_{2.5}$ sebelum Asian Games ke-18 di Jakarta Selatan sebesar $67,9 \mu \mathrm{g} / \mathrm{m}^{3}$ melebihi ambang batas yang ditetapkan oleh Peraturan Pemerintah Republik Indonesia No. 41 Tahun 1999 tentang Pengendalian Pencemaran Udara.

3) Terjadi penurunan signifikan konsentrasi $\mathbf{P M}_{2.5}$ pada saat dan setelah Asian Games ke-18 di Jakarta Pusat dan Selatan dibandingkan kondisi sebelum Asian Games ke18.

4) Penurunan konsentrasi terbesar antara periode sebelum dan setelah Asian Games ke-18 tejadi pada hari Selasa di kedua titik pengamatan. Sedangkan penurunan konsentrasi terendah terjadi pada hari Minggu di Jakarta Pusat dan hari Jumat di Jakarta Selatan.

\subsection{SARAN}

Penelitian ini terbatas pada periode 23 Juli sampai 23 September 2018. Hasil yang lebih baik dapat diperoleh untuk data yang lebih panjang melalui pertimbangan faktor meteorologis seperti hujan dan suhu udara.

\section{DAFTAR PUSTAKA}

Aljazeera. 2018. Air pollution welcomes athletes in Jakarta for Asian Games. https://www.aljazeera.com/blogs/asia/2018/08/air-pollution-welcomes-athletesjakarta-asian-games-180816142658871.html. Diakses tanggal 01 November 2018.

Dockery, D. W., Pope, C. A., Xu, X., Spengler, J. D., Ware, J. H., Fay, M. E., Ferris Jr, B. G. dan Speizer, F. E. 1993. An association between air pollution and mortality in six US cities. New England journal of medicine. Vol. 329. Halaman 1753-1759. 


\section{STATMAT}

(Jurnal Statistika dan Matematika)

Dong-Qun, X. dan Wen-Li, Z. 2004. Monitoring of pollution of air fine particles (PM2. 5) and study on their genetic toxicity. Biomedical Environmental Sciences. Vol. 17. Halaman 452-458.

Gibbons, J. D. dan Chakraborti, S. 2003. Edisi ke 4. Marcel Dekker, Inc.: New York.

ISO. 1995. International Organization for Standardization (ISO) 7708 Particle size definitions for health related sampling. ISO: Geneva, Switzerland.

Kompas. 2018. Selama Asian Games, Sistem Ganjil Genap Berlaku 15 Jam Per Hari. https://megapolitan.kompas.com/read/2018/05/23/17583031/selama-asiangames-sistem-ganjil-genap-berlaku-15-jam-per-hari. Diakses tanggal 01 November 2018.

Kusminingrum, N. dan Gunawan, G. 2008. Polusi udara akibat aktivitas kendaraan bermotor di jalan perkotaan Pulau Jawa dan Bali. Laporan penelitian, Puslitbang Jalan dan Jembatan. Vol. Halaman Kementerian Pekerjaan Umum: Bandung.

Nugroho, S. 2007. Dasar Dasar Metode Statistika. Grasindo: Bengkulu.

Republik Indonesia. 1999. Peraturan Pemerintah Republik Indonesia No. 41 Tahun 1999 tentang Pengendalian Pencemaran Udara. Sekretaris Kabinet Republik Indonesia: Jakarta.

Reuters. 2018. From cloud seeding to vehicle curbs, Indonesia fights pollution ahead of Asian Games. https://www.reuters.com/article/us-games-asia-pollution/fromcloud-seeding-to-vehicle-curbs-indonesia-fights-pollution-ahead-of-asian-gamesidUSKBN1K713D. Diakses tanggal 1 November 2018.

Sugiyono. 2006. Statistika untuk penelitian. CV. Alfabeta: Bandung.

Tiwary, A. dan Jeremy, C. 2010. Air pollution: measurement, modelling and mitigation. Edisi ke 3. Routledge Press: Oxford.

Vallero, D. A. 2014. Fundamentals of air pollution. Edisi ke 4. Academic press: London.

Wilks, D. S. 2011. Statistical methods in the atmospheric sciences. Vol. 100. Academic press: Oxford. 
STATMAT

(Jurnal Statistika dan Matematika)
P-ISSN: 2655-3724

STATMAT (Jurnal Statistika dan Matematika), Vol. 1, No. 1, Januari 2019 Halaman: 44-62

@ Prodi S-1 Matematika FMIPA Unpam

Zar, J. H. 1996. Biostatistical analysis. Edisi ke 3. Prentice Hall International, Inc.: New Jersey. 